\title{
Successful Deer Management in Scotland Requires Less Conflict Not More
}

\author{
Hannah Kirkland ${ }^{1 *}$, Darragh Hare ${ }^{1,2,3}$, Mike Daniels $^{4}$, Miha Krofel ${ }^{5}$, Shaila Rao ${ }^{6}$, \\ Tatiana Chapman ${ }^{1}$ and Bernd Blossey ${ }^{2}$ \\ ${ }^{1}$ Wildlife Conservation Research Unit, Department of Zoology, The Recanati-Kaplan Centre, Oxford University, Oxford, \\ United Kingdom, ${ }^{2}$ Department of Natural Resources and the Environment, Cornell University, Ithaca, NY, United States, \\ ${ }^{3}$ Center for Conservation Social Sciences, Cornell University, Ithaca, NY, United States, ${ }^{4}$ The John Muir Trust, Pitlochry, \\ United Kingdom, ${ }^{5}$ Department of Forestry, Biotechnical Faculty, University of Ljubljana, Ljubljana, Slovenia, ${ }^{6}$ National Trust \\ for Scotland, Mar Lodge Estate, Braemar, United Kingdom
}

What would successful deer management look like in Scotland? To some, flourishing populations of native wild deer represent success. But to others, negative impacts such as damage to woodlands and peatlands, agricultural and forestry losses, deervehicle collisions, and facilitating Lyme disease spread represent failure. Conflicting interests and incentives among people involved in deer management mean a common definition of success, and therefore clear management targets, remain elusive. While some environmental groups urgently call for an increase in the number of deer culled (shot) each year, other stakeholders aim to maximize deer numbers. Overcoming this governance failure will require clearly articulated, scientifically valid, and socially acceptable socio-ecological objectives to be co-produced by a broad range of stakeholders. Systematic monitoring of deer impacts will also be needed to evaluate the ability of specific management interventions to achieve defined objectives. Reintroducing Eurasian lynx (Lynx lynx) has been suggested as a means to reduce deer numbers and their negative ecological and socioeconomic impacts. However, evidence of lynx impacts on deer numbers, deer impacts, and social conflicts over deer suggest lynx reintroduction alone would not effectively reduce negative impacts of deer in Scotland, though it could be part of a broader solution. In the short-term, achieving sustainable numbers of deer in Scotland will require a substantial increase in the number of deer culled and effective changes to the way deer management is incentivized, regulated, implemented, and monitored.

Keywords: wildlife governance, deer management, lynx reintroduction, ecological restoration, conservation conflict

\section{DEER MANAGEMENT: A CONSERVATION CONFLICT}

Scotland's thriving wild deer populations, like those elsewhere in Europe and North America, are at the center of a persistent conservation conflict. This conflict centers mostly around red deer (Cervus elaphus), Scotland's most ecologically, economically, and culturally important deer species, but also concerns roe deer (Capreolus capreolus) (MacMillan and Phillip, 2010; Pepper et al., 2019). In the absence of native large carnivores, Scotland's deer populations have steadily expanded for decades as disease, starvation, road kills, and stalking (shooting) have failed to keep numbers in 
check. Expanding deer populations are associated with ecological and socio-economic costs, and conservationists are calling for a drastic increase in the number of deer culled (shot) to address associated negative impacts (Scottish Environment, 2020).

Deer can bring environmental and social benefits to rural Scotland through seed dispersal, creation of microsites for seed germination, job creation, income from hunting and tourism, and their aesthetic and cultural appeal (Gill and Beardall, 2001; PACEC, 2006; Dandy et al., 2009; Shaw et al., 2010). However, large deer populations can negatively affect vegetation dynamics, community composition, biodiversity and ecosystem process, and threaten human health and the economy (Gill and Beardall, 2001; Côté et al., 2004; MacMillan and Phillip, 2008; Glenn et al., 2019). Under high deer densities, many of Scotland's native tree species, such as Scots pine (Pinus sylvestris), rowan (Sorbus aucuparia), juniper (Juniperus communis), and dwarf birch (Betula nana) are failing to regenerate (Miller et al., 1982; Scott, 2001; Tanentzap et al., 2013; Rao, 2017). Understory shrubs, such as blaeberry (Vaccinium myrtillus), are consistently cropped, generating knock-on effects for the species that rely on them (Baines et al., 1994). Deer impacts extend beyond direct consumption of primary producers. Deer browsing on downy birch (Betula pubescens) impacts nutrient cycling by slowing decomposition of leaf litter (Harrison and Bardgett, 2003). Deer also affect carbon cycles by reducing plant biomass available for photosynthesis and influencing litter decomposition (Hirst, 2021).

There is strong evidence that increases in deer populations are facilitating the spread of ticks, such as Ixodes ricinus, the most important vector for zoonotic pathogens in Europe, including Lyme disease (Kirby et al., 2004; Scharlemann et al., 2008; Gilbert et al., 2012). Expanding deer numbers are also associated with an increase in deer-vehicle collisions, costing millions of pounds a year in Scotland, and causing serious injuries and fatalities to both humans and deer (Putman, 2012). Deer can significantly damage grasses, cereal crops, and orchards and the forestry sector must spend millions of pounds annually on deer management, including culling and fencing, to enable forest regeneration (Pepper et al., 2019).

Despite known socio-ecological costs associated with high deer densities, attempts to create a sustainable system of deer management in Scotland have largely been unsuccessful. At the heart of this problem are competing values and objectives among those responsible for deer management, as landowners, deer stalkers, conservationists, and government officials have, for decades, been unable to reach consensus over what successful deer management in Scotland should look like. Although the Scottish Government has legislative responsibility for ensuring the sustainable management of deer, landowners, who own and control hunting rights, often have objectives that can be in tension with broader public interests (MacMillan and Leitch, 2008; Pepper et al., 2019). NatureScot, the government agency responsible for enforcing deer legislation, has legal powers to enforce deer culling, but relies largely on voluntary cooperation from landowners to engage in deer culls. Individual landowners set their own cull targets, but if they fail to meet targets, NatureScot does not sanction them. With extensive areas of the
Scottish countryside managed as private deer stalking estates, many landowners have economic and cultural incentives to maximize deer abundance, particularly of red deer stags (males) for trophy hunting (MacMillan and Leitch, 2008; Glass et al., 2013 , 2019). Consequently, many landowners set cull targets too low to achieve sustainable deer numbers and impacts (Albon et al., 2017; Pepper et al., 2019). Those who voluntary increase cull levels to address the socio-ecological impacts of deer often fail to impact deer at the landscape level where neighboring properties pursue alternative objectives (Albon et al., 2017; Pepper et al., 2019).

In the absence of clear and agreed socio-ecological benchmarks for success, those involved in deer management lack effective and reliable evaluation metrics. At present, management outcomes are evaluated largely based on deer data, such as density and cull numbers, at the individual property level. However, cull numbers and population density alone are often poor predictors of the impacts of deer at a landscape level because of feedbacks among deer populations, altered vegetation communities, ecosystem properties, and the presence of other stressors (Putman et al., 2011; Tanentzap et al., 2012, 2013; Blossey et al., 2017). Some landowners do assess ecological impacts of deer on their properties, but assessment protocols often vary, making it difficult to make meaningful comparisons and conclusions at landscape scales (Campbell and Marchbank, 2013; Armstrong and Holl, 2015). Furthermore, assessment data are often not made publicly available, with evidence of deer impacts on rare and sensitive species and ecosystems, such as aspen, peatlands, and montane woodlands, particularly scarce. Evidence of deer impacts therefore fails to provide an effective tool for guiding management and policy decisions beyond the very local scale.

\section{A VISION FOR THE FUTURE: CO-PRODUCING A DEFINITION OF SUCCESS}

In recent years, the Scottish Government has tried to encourage landowners to increase the number of deer culled each year. However, despite an increase in the number of deer culled in recent years, deer densities continue to be too high to achieve positive socio-ecological outcomes across much of Scotland (Albon et al., 2017; Pepper et al., 2019). Incentive based policies, such as culling or venison subsidies, taxing landowners who do not meet targets, "tradeable obligations" that would oblige landowners to shoot deer but allow them to trade their "obligations" with other estates, or a "cull approval system," requiring landowners to obtain approval for their planned cull prior to being given hunting permits, could encourage landowners to shoot more deer (MacMillan, 2004; MacMillan et al., 2010; Pepper et al., 2019). However, policy changes that fail to address the underlying conflicting values and agendas of affected stakeholders and power relations between them could exacerbate tensions between these groups and undermine potential for cooperation over deer, particularly among some landowners and deer stalking communities (MacMillan, 2004; 
Hill, 2021). In the past, reluctance to create political fall-out has prevented successive public agencies responsible for deer management from exercising existing powers to enter properties and cull deer in order to protect Scotland's natural heritage (MacMillan, 2004).

Sustainable solutions to the deer crisis must account for deep histories of stakeholder conflict over deer (Hobbs, 2009; Phillip et al., 2009; MacMillan et al., 2010; Davies and White, 2012). This will require greater clarity and, where possible, consensus among relevant stakeholder groups regarding desirable ecological and social outcomes from deer management (Ceauşu et al., 2018). Here we refrain from making specific recommendations on how to solve the deer crisis in Scotland, because such recommendations should emerge from a deliberative process through which a broad range of stakeholders, including stalkers, landowners, scientists, conservationists, and government officials, can co-produce a definition of successful deer management (Redpath et al., 2015). To be effective, this definition should include objectives for ecological, socioeconomic, and human health outcomes that are clearly articulated, informed by best available evidence, and perceived to be legitimate by affected stakeholders (Forstchen and Smith, 2014; Hare et al., 2017; Bennett and Satterfield, 2018; Pomeranz et al., 2021). Although objectives are unlikely to fully satisfy all affected stakeholders all of the time, they will be more legitimate, and therefore acceptable, if stakeholders and the public more generally, perceive the process of identifying them to be fair, and can accept that objectives reflect trade-offs between multiple competing perspectives, interests, and values (Forstchen and Smith, 2014; Ceauşu et al., 2018; Pomeranz and Stedman, 2020). When subsequent deer management activities make demonstrable progress toward these objectives, those activities can be considered successful.

Adaptive, evidence-based deer management will require consistent, reliable metrics, and protocols for evaluating whether management options have successfully achieved articulated objectives. Repeated and systematic collection of socio-ecological deer impacts (e.g., incidences of Lyme disease and deer-vehicle collision, browse rates, etc.) will need to complement data collected on deer abundance and cull numbers as metrics for evaluating success. These metrics will enable decision-makers to review and adjust, where necessary, deer management and policy decisions based on deer impacts. Data collected across ecological and management contexts will need to be properly collated and synthesized at a regional and national scale to serve as an effective tool for informing management and policy-decisions across the wider landscape.

\section{LYNX REINTRODUCTION: SOLUTION OR ILLUSION?}

Some environmental groups argue for reintroduction of extirpated native large carnivores, particularly Eurasian lynx $(\operatorname{Lyn} x \operatorname{lynx})$ (hereafter "lynx"), claiming that they would help reduce deer numbers and negative impacts of deer (Amos, 2021). Although lynx might be the least controversial of Scotland's native but extirpated large carnivores, lynx reintroduction could exacerbate stakeholder conflicts, particularly among sheep farmers, and those involved in deer hunting (Odden et al., 2008; Breitenmoser et al., 2010; van Eeden et al., 2018). While there are many ecological and economic arguments for and against reintroducing lynx to Scotland, some pro-lynx interests emphasize the capacity of lynx to help solve Scotland's deer crisis through directly consuming deer and indirectly benefiting plant species that deer eat or trample. Whether lynx reintroduction to Scotland would help achieve positive socio-ecological objectives for deer management would depend on the impact of lynx on deer numbers, deer impacts, and enduring social conflicts over deer. Arguments that overstate potential impacts of lynx on deer could generate unrealistic and unachievable expectations.

Evidence from elsewhere in Europe suggest that lynx would do little to reduce red deer numbers in Scotland. Across their European range, lynx have a strong association to woodland habitat, making it unlikely that they would predate on red deer in Scotland, which frequently occupy open hill habitats (Breitenmoser et al., 2000; Jędrzejewski et al., 2002; Albon et al., 2017). However, although lynx predation on red deer is usually focused on calves, Scottish red deer are smaller than those in mainland Europe and might therefore be more manageable prey for lynx where they occupy woodland habitat (Mitchell et al., 1977). Nevertheless, throughout their European range, lynx display a strong preference for hunting roe deer (Nowicki, 1997). Lynx can effectively limit roe deer populations, particularly in harsh climates, and can significantly increase kill rates and concentration of kills when encountering abundant and potentially naïve prey (Breitenmoser and Haller, 1993; Jędrzejewski et al., 1993; Okarma et al., 1997; Melis et al., 2009, 2010; Andrén and Liberg, 2015; Dula and Krofel, 2020). However, this does not necessarily predict lynx-roe deer dynamics in Scotland. The extent to which a lynx reintroduction could reduce Scotland's roe deer populations in the long term is not wellunderstood.

Lynx ability to bring about a vegetation response through consumptive and non-consumptive impacts on deer has been poorly studied. Existing evidence of the behavioral responses of roe deer to the presence of lynx suggests lynx may have some non-consumptive effects on deer behavior, particularly when in immediate risk of predation, but whether this can translate to a vegetation response requires further study (Samelius et al., 2013; Dupke et al., 2017; Eccard et al., 2017; Gehr et al., 2018; van Beeck Calkoen et al., 2021). Detailed monitoring of ungulate population densities, behavior and their impact on vegetation throughout all phases of a potential reintroduction to Scotland would be essential for setting realistic objectives and evaluating progress toward them. This holds true for anywhere that carnivore reintroductions are being explored as a mechanism for reducing or controlling ungulate populations.

Although we cannot fully predict the potential impacts of lynx in Scotland, on the strength of existing evidence, it does not appear that lynx reintroduction would provide a silver bullet for overcoming Scotland's deer crisis, though it may be helpful. We are concerned that outsized expectations and promises that lynx reintroduction would suffice to solve the deer crisis could 
undermine, rather than support, progress toward identifying, and meeting broader conservation objectives, including those associated with deer. With many of the stakeholders involved in deer management likely to be those also most affected by lynx reintroduction (e.g., hunters, conservationists, and rural landowners), any eventual reintroduction predicated on promises of positive ecological impacts could exacerbate fragile cooperation among deer stakeholders if such impacts do not materialize. Such an overpromising but underachieving scenario could also undermine trust in conservation institutions (Crowley et al., 2017). Conflict with hunters over the perceived threat posed to roe deer by lynx is a significant driver of illegal killing of lynx in Europe, and with a large amount of privatelyowned land in Scotland, poaching could be a significant threat to any reintroduced population of lynx (Breitenmoser et al., 2010). Though predation on game birds by lynx is relatively uncommon in areas of high ungulate availability, populations of game birds are maintained at high densities across much of Scotland for sport hunting, and perceived impacts among hunters could be another source of tension (Nowicki, 1997; Aebischer, 2019).

There are other arguments for the reintroduction of lynx to Scotland beyond their impacts on deer. Restoring an extirpated native species could be considered a worthwhile conservation endeavor in its own right, as long as it is socially acceptable and ecologically viable. Through selective hunting of deer in poor condition, lynx could maintain healthy deer populations, they could help limit numbers of mesopredators such as foxes, and provide economic benefits to rural areas through ecotourism (Helldin et al., 2006; Hetherington, 2006; Krofel et al., 2014). Any eventual lynx reintroduction would need to consider the likelihood of these impacts as part of a larger effort to identify appropriate ecological and social objectives for defining and evaluating success. Just as with the deer crisis, we recommend a deliberative process to identify relevant ecological and social benchmarks, clear indicators of success and accurate assessment tools. This process would help gauge the overall acceptability of lynx reintroduction to Scotland and identify social conflicts that may arise and how to mitigate them.

\section{REFERENCES}

Aebischer, N. J. (2019). Fifty-year trends in UK hunting bags of birds and mammals, and calibrated estimation of national bag size, using GWCT's National Gamebag Census. Eur. J. Wildl. Res. 65, 64. doi: 10.1007/s10344-0191299-x

Albon, S. D., McLeod, J., Potts, J., Brewer, M., Irvine, J., Towers, M., et al. (2017). Estimating National Trends and Regional Differences in Red Deer Density on Open-Hill Ground in Scotland: Identifying the Causes of Change and Consequences for Upland Habitats. Inverness: Scottish Natural Heritage Commissioned Report No 981. Available online at: https://www.nature. scot/snh-research-report-1149-updating-estimates-national- $\sim$ trends-andregional-differences-red-deer (accessed August 30, 2021).

Amos, I. (2021). Should Scotland once again have big cats roaming wild in Highland forests? Scotsman. Available online at: https://www. scotsman.com/news/environment/should-scotland-once-again-havebig-cats-roaming-wild-highland-forests-3106020 (accessed August 1 7, 2021).

\section{A WAY FORWARD}

Conservation conflicts often arise when stakeholders perceive conservation objectives to threaten other objectives, such as livelihood objectives (Redpath et al., 2015). They can also arise when stakeholders perceive such objectives to be based on external values imposed upon them. In Scotland, perceptions, values, and expectations regarding deer management are multifaceted, deep rooted, and reflect cultures, traditions, and preferences that extend far beyond deer (Hobbs, 2009; MacMillan et al., 2010; Hare et al., 2021). We anticipate that overcoming Scotland's deer crisis will require a substantial increase in the number of deer culled as part of a broader solution that could include lynx reintroduction. However, opposition to these changes, and conservation and rewilding more generally, might have more to do with perceptions of illegitimacy and distrust toward conservationists, rather than any specific conservation aims and objectives (MacMillan and Leitch, 2008). Attempts to establish a sustainable system of deer management in Scotland that fail to address these underlying tensions seem unlikely to succeed. We envision a process for co-producing definitions of success and associated objectives and metrics that respects and sensitively accounts for these differences. We hope this process will pave the way toward more sustainable deer management institutions in Scotland, which are grounded in evidence and prioritize positive impacts on Scotland's ecosystems and the people who depend on them.

\section{DATA AVAILABILITY STATEMENT}

The original contributions presented in the study are included in the article/supplementary material, further inquiries can be directed to the corresponding author/s.

\section{AUTHOR CONTRIBUTIONS}

$\mathrm{HK}, \mathrm{DH}, \mathrm{BB}$, and $\mathrm{MD}$ conceived the manuscript. HK led the writing. All authors contributed to formulating the arguments, writing, and reviewing drafts.

Andrén, H., and Liberg, O. (2015). Large impact of Eurasian lynx predation on roe deer population dynamics. PLOS ONE 10, e0120570. doi: 10.1371/journal.pone.0120570

Armstrong, H., and Holl, K. (2015). Assessing the impact of deer on woodlands: a new method. Reforesting Scotl. 52, 11-13. Available online at: https:// reforestingscotland.org/wp-content/uploads/2015/09/Armstrong-p11-13.pdf (accessed August 15, 2021).

Baines, D., Sage, R. B., and Baines, M. M. (1994). The implications of red deer grazing to ground vegetation and invertebrate communities of Scottish native pinewoods. J. Appl. Ecol. 31, 776-783. doi: 10.2307/2404167

Bennett, N. J., and Satterfield, T. (2018). Environmental governance: a practical framework to guide design, evaluation, and analysis. Conserv. Lett. 11, e12600. doi: $10.1111 /$ conl.12600

Blossey, B., Dávalos, A., and Nuzzo, V. (2017). An indicator approach to capture impacts of white-tailed deer and other ungulates in the presence of multiple associated stressors. AoB Plants 9, 1-16. doi: 10.1093/aobpla/plx034

Breitenmoser, U., Breitenmoser-Würsten, C., Okarma, H., Kaphegyi, T., KaphegyiWallmann, U., Müller, U. M., et al. (2000). The Action Plan for the Conservation 
of the Eurasian Lynx (Lynx Lynx) in Europe. Strasbourg: Council of Europe Publishing, Nature and Environmental Series No. 112 Available online at: https://www.researchgate.net/publication/228776242_Action_Plan_for_ the_Conservation_of_the_Eurasian_Lynx_in_Europe_Lynx_lynx (accessed August 31, 2021).

Breitenmoser, U., and Haller, H. (1993). Patterns of predation by reintroduced European lynx in the Swiss Alps. J. Wildl. Manage. 57, 135-144. doi: $10.2307 / 3809010$

Breitenmoser, U., Ryser, A., Molinari-Jobin, A., Zimmermann, F., Haller, H., and Molinari, P. (2010). "The changing impact of predation as a source of conflict between hunters and reintroduced lynx in Switzerland," in Biology and Conservation of Wild Felids, eds D. W. Macdonald and A. J. Loveridge (Oxford: Oxford University Press) 493-506.

Campbell, D., and Marchbank, M. (2013). A Deer Population and Habitat-Impact Assessment of the Monadhliath SAC, Inverness-Shire, UK. Inverness: Scottish Natural Heritage Commissioned Report No. 527. Available online at: https:// media.nature.scot/record/ 9ec3d79826 (accessed August 27, 2021).

Ceauşu, S., Graves, R. A., Killion, A. K., Svenning, J. C., and Carter, N. H. (2018). Governing trade-offs in ecosystem services and disservices to achieve humanwildlife coexistence. Conserv. Biol. 33, 543-553. doi: 10.1111/cobi.13241

Côté, S. D., Rooney, T. P., Tremblay, J. P., Dussault, C., and Waller, D. M. (2004). Ecological impacts of deer overabundance. Annu. Rev. Ecol. Evol. Syst. 35, 113-147. doi: 10.1146/annurev.ecolsys.35.021103.105725

Crowley, S. L., Hinchliffe, S., and McDonald, R. A. (2017). Conflict in invasive species management. Front. Ecol. Environ. 15, 133-141. doi: 10.1002/fee.1471

Dandy, N., Ballantyne, S., Moseley, D., and Quine, C. (2009). The management of roe deer in peri-urban Scotland: final report. Forest Research. Available online at: http://www.forestresearch.gov.uk/fr/INFD-7D4AXC (accessed August 31, 2021).

Davies, A. L., and White, R. M. (2012). Collaboration in natural resource governance: reconciling stakeholder expectations in deer management in Scotland. J. Environ. Manage. 112, 160-169. doi: 10.1016/j.jenvman.2012.07.032

Dula, M., and Krofel, M. (2020). A cat in paradise: hunting and feeding behaviour of Eurasian lynx among abundant naive prey. Mamm. Biol. 100, 685-690. doi: $10.1007 /$ s42991-020-00070-6

Dupke, C., Bonenfant, C., Reineking, B., Hable, R., Zeppenfeld, T., Ewald, M., et al. (2017). Habitat selection by a large herbivore at multiple spatial and temporal scales is primarily governed by food resources. Ecography (Cop.). 40, 1014-1027. doi: 10.1111/ecog.02152

Eccard, J. A., Meißner, J. K., and Heurich, M. (2017). European roe deer increase vigilance when faced with immediate predation risk by Eurasian lynx. Ethology 123, 30-40. doi: 10.1111/eth.12420

Forstchen, A. B., and Smith, C. A. (2014). The essential role of human dimensions and stakeholder participation in states fulfillment of public trust responsibilities. Hum. Dimens. Wildl. 19, 417-426. doi: $10.1080 / 10871209.2014 .940561$

Gehr, B., Hofer, E. J., Ryser, A., Vimercati, E., Vogt, K., and Keller, L. F. (2018). Evidence for nonconsumptive effects from a large predator in an ungulate prey? Behav. Ecol. 29, 724-735. doi: 10.1093/beheco/ary031

Gilbert, L., Maffey, G. L., Ramsay, S. L., and Hester, A. J. (2012). The effect of deer management on the abundance of Ixodes ricinus in Scotland. Ecol. Appl. 22, 658-667. doi: 10.1890/11-0458.1

Gill, R. M. A., and Beardall, V. (2001). The impact of deer on woodlands: the effects of browsing and seed dispersal on vegetation structure and composition. Forestry. 74, 209-218. doi: 10.1093/forestry/74.3.209

Glass, J., McMorran, R., and Thomson, S. (2019). The Effects Associated With Concentrated and Large Scale Land Ownership in Scotland: A Research Review. Report Prepared for Scottish Land Commission. Edinburgh: Scotland's Rural College. Available online at: https://www.landcommission.gov.scot/ downloads/5dd7d807b8768_Research-Review-Concentrated-ownershipfinal-20190320.pdf (accessed August 31, 2021).

Glass, J. H., Scott, A. J., and Price, M. F. (2013). The power of the process: coproducing a sustainability assessment toolkit for upland estate management in Scotland. Land Use Policy 30, 254-265. doi: 10.1016/j.landusepol.2012. 03.024

Glenn, S., MacKessack-Leitch, J., Glass, J., and McMorran, R. (2019). Investigation into the Issues Associated With Large Scale and Concentrated Landownership in Scotland. Scottish Land Commission. Available online at: https://www. landcommission.gov.scot/downloads/5dd7d6fd9128e_Investigation-IssuesLarge-Scale-and-Concentrated-Landownership-20190320.pdf (accessed August 31, 2021).

Hare, D., Daniels, M., and Blossey, B. (2021). Public perceptions of deer management in Scotland. Front. Conserv. Sci. 2:781546. doi: $10.3389 /$ fcosc. 2021.781546

Hare, D., Decker, D. J., Smith, C. A., Forstchen, A. B., and Jacobson, C. A. (2017). Applying public trust thinking to wildlife governance in the United States: challenges and potential solutions. Hum. Dimens. Wildl. 22, 506-523. doi: 10.1080/10871209.2017.1359864

Harrison, K. A., and Bardgett, R. D. (2003). How browsing by red deer impacts on litter decomposition in a native regenerating woodland in the Highlands of Scotland. Biol. Fertil. Soils 38, 393-399. doi: 10.1007/s00374-003-0667-5

Helldin, J. O., Liberg, O., and Glöersen, G. (2006). Lynx (Lynx lynx) killing red foxes (Vulpes vulpes) in boreal Sweden - frequency and population effects. J. Zool. 270, 657-663. doi: 10.1111/J.1469-7998.2006.00172.X

Hetherington, D. (2006). The lynx in Britain's past, present and future. Ecos 27, 66-74. Available online at: https://www.roydennis.org/o/wp-content/ uploads/2011/10/The-Lynx-in-Britains-Past-Present-Future.pdf (accessed August 17, 2021).

Hill, C. M. (2021). Conflict Is integral to human-wildlife coexistence. Front. Conserv. Sci. 2:734314. doi: 10.3389/fcosc.2021.734314

Hirst, C. (2021). Deer in a Changing Climate - How do Wild Deer Affect Carbon Sequestration in Scottish Woodlands? Edinburgh: University of Edinburgh. doi: $10.7488 /$ era/977

Hobbs, R. (2009). Woodland restoration in Scotland: ecology, history, culture, economics, politics and change. J. Environ. Manage. 90, 2857-2865. doi: 10.1016/j.jenvman.2007.10.014

Jędrzejewski, W., Schmidt, K., Milkowski, L., Jedrzejewska, B., and Okarma, H. (1993). Foraging by lynx and its role in ungulate mortality: the local (Białowieza Forest) and the Palaearctic viewpoints. Acta Theriol. (Warsz). 38, 385-403. doi: 10.4098/AT.arch.93-30

Jędrzejewski, W., Schmidt, K., Okarma, H., and Kowalczyk, R. (2002). Movement pattern and home range use by the Eurasian lynx in Białowieza Primeval Forest (Poland). Ann. Zool. Fennici 39, 29-41.

Kirby, A. D., Smith, A. A., Benton, T. G., and Hudson, P. J. (2004). Rising burden of immature sheep ticks (Ixodes ricinus) on red grouse (Lagopus lagopus scoticus) chicks in the Scottish uplands. Med. Vet. Entomol. 18, 67-70. doi: 10.1111/j.0269-283X.2004.0479.x

Krofel, M., Jerina, K., Kljun, F., Kos, I., Potočnik, H., RaŽen, N., et al. (2014). Comparing patterns of human harvest and predation by Eurasian lynx Lynx lynx on European roe deer Capreolus capreolus in a temperate forest. Eur. J. Wildl. Res. 60, 11-21. doi: 10.1007/s10344-013-0745-4

MacMillan, D. (2004). Tradeable hunting obligations-a new approach to regulating red deer numbers in the Scottish Highlands? J. Environ. Manage. 71, 261-270. doi: 10.1016/j.jenvman.2004.03.005

MacMillan, D. C., and Leitch, K. (2008). Conservation with a gun: understanding landowner attitudes to deer hunting in the Scottish Highlands. Hum. Ecol. 36, 473-484. doi: 10.1007/s10745-0089170-9

MacMillan, D. C., Leitch, K., Wightman, A., and Higgins, P. (2010). The management and role of highland sporting estates in the early twenty-first century: The owner's view of a unique but contested form of land use. Scottish Geogr. J. 126, 24-40. doi: 10.1080/14702540903499124

MacMillan, D. C., and Phillip, S. (2008). Consumptive and non-consumptive values of wild mammals in Britain. Mamm. Rev. 38, 189-204. doi: 10.1111/j.1365-2907.2008.00124.x

MacMillan, D. C., and Phillip, S. (2010). Can economic incentives resolve conservation conflict: the case of wild deer management and habitat conservation in the Scottish Highlands. Hum. Ecol. 38, 485-493. doi: 10.1007/s10745-010-9332-4

Melis, C., Basille, M., Herfindal, I., Linnell, J. D. C., Odden, J., Gaillard, J.-M., et al. (2010). Roe deer population growth and lynx predation along a gradient of environmental productivity and climate in Norway. Écoscience 17, 166-174. doi: $10.2980 / 17-2-3314$

Melis, C., Jędrzejewska, B., Apollonio, M., Bartoń, K. A., Jędrzejewski, W., Linnell, J. D. C., et al. (2009). Predation has a greater impact in less productive 
environments: variation in roe deer, Capreolus capreolus, population density across Europe. Glob. Ecol. Biogeogr. 18, 724-734. doi: 10.1111/j.1466-8238.2009. 00480.x

Miller, G. R., Kinnaird, J. W., and Cummins, R. P. (1982). Liability of saplings to browsing on a red deer range in the Scottish Highlands. J. Appl. Ecol. 19, 941-951. doi: 10.2307/2403295

Mitchell, B., Staines, B., and Welch, D. (1977). Ecology of Red Deer: A Research Review Relevant To Their Management in Scotland. Cambridge: Institute of Terrestrial Ecology.

Nowicki, P. (1997). Food habit and diet of the lynx (Lynx lynx) in Europe. Eur. J. Wildl. Res. 2. 161-166.

Odden, J., Herfindal, I., Linnell, J. D. C., and Andersen, R. (2008). Vulnerability of domestic sheep to lynx depredation in relation to roe deer density. J. Wildl. Manage. 72, 276-282. doi: 10.2193/2005-537

Okarma, H., Jędrzejewski, W., Schmidt, K., Kowalczyk, R., and Jędrzejewska, B. (1997). Predation of Eurasian lynx on roe deer and red deer in Bialowieza Primeval Forest, Poland. Acta Theriol. (Warsz). 42, 203-224. doi: 10.4098/AT.arch.97-22

PACEC (2006). The Contribution of Deer Management to the Scottish Economy. Report commissioned by the Scottish Association of Deer Management Groups. Cambridge: PACEC Available online at: http://www. deer-management.co.uk/wp-content/uploads/2014/03/PACEC-Report.pdf (accessed August 31, 2021).

Pepper, S., Barbour, A., and Glass, J. (2019). The Management of Wild Deer in Scotland. Edinburgh: Deer Working Group Available online at: https://www.gov.scot/publications/management-wild-deer-scotland/pages/ 5/ (accessed July 28, 2021).

Phillip, S., Dandy, N., Gill, R., and MacMillan, D. C. (2009). Is legislation a barrier to the sustainable management of game species? A case study of wild deer in Britain. J. Environ. Plan. Manag. 52, 993-1012. doi: 10.1080/09640560903327351

Pomeranz, E. F., Hare, D., Decker, D. J., Forstchen, A. B., Jacobson, C. A., Smith, C. A., et al. (2021). Successful wildlife conservation requires good governance. Front. Conserv. Sci. 2:753289. doi: 10.3389/fcosc.2021.753289

Pomeranz, E. F., and Stedman, R. C. (2020). Measuring good governance: piloting an instrument for evaluating good governance principles. J. Environ. Policy Plan. 22, 428-440. doi: 10.1080/1523908X.2020.1753181

Putman, R. (2012). Scoping the Economic Benefits and Costs of Wild Deer and Their Management in Scotland. Inverness: Scottish Natural Heritage Commissioned Report No. 526. SNH Commissioned report No. 526 Available online at: https:// media.nature.scot/record/\$ $\$$ sim $\$$ f6377f7895 (accessed August 31, 2021).

Putman, R., Watson, P., and Langbein, J. (2011). Assessing deer densities and impacts at the appropriate level for management: a review of methodologies for use beyond the site scale. Mamm. Rev. 41, 197-219. doi: 10.1111/j.1365-2907.2010.00172.x

Rao, S. J. (2017). Effect of reducing red deer Cervus elaphus density on browsing impact and growth of Scots pine Pinus sylvestris seedlings in semi-natural woodland in the Cairngorms, UK. Conserv. Evid. 14, 22-26. Available online at: http://t.www.conservationevidence.com/reference/pdf/6153

Redpath, S. M., Bhatia, S., and Young, J. (2015). Tilting at wildlife: reconsidering human-wildlife conflict. Oryx 49, 222-225. doi: 10.1017/S0030605314000799
Samelius, G., Andrén, H., Kjellander, P., and Liberg, O. (2013). Habitat selection and risk of predation: Re-colonization by lynx had limited impact on habitat selection by roe deer. PLOS ONE 8, e75469. doi: 10.1371/journal.pone.0075469

Scharlemann, J. P. W. W., Johnson, P. J., Smith, A. A., Macdonald, D. W., and Randolph, S. E. (2008). Trends in ixodid tick abundance and distribution in Great Britain. Med. Vet. Entomol. 22, 238-247. doi: 10.1111/j.1365-2915.2008.00734.x

Scott, D. (2001). Recovery of a dwarf birch (Betula nana) population following reduction in grazing by red deer (Cervus elaphus). Bot. J. Scotl. 53, 155-167. doi: $10.1080 / 03746600108685020$

Scottish Environment (2020). Managing Deer for Climate, Communities and Conservation. Perth: Scottish Environment. Available online at: https:// www.scotlink.org/publication/managing-deer-for-climate-communities-andconservation/

Shaw, R. F., Iason, G. R., Pakeman, R. J., and Young, M. R. (2010). Regeneration of Salix arbuscula and Salix lapponum within a large mammal exclosure: the impacts of microsite and herbivory. Restor. Ecol. 18, 1-9. doi: 10.1111/j.1526-100X.2010.00720.x

Tanentzap, A. J., Kirby, K. J., and Goldberg, E. (2012). Slow responses of ecosystems to reductions in deer (Cervidae) populations and strategies for achieving recovery. For. Ecol. Manage. 264, 159-166. doi: 10.1016/j.foreco.2011. 10.005

Tanentzap, A. J., Zou, J., and Coomes, D. A. (2013). Getting the biggest birch for the bang: restoring and expanding upland birchwoods in the Scottish Highlands by managing red deer. Ecol. Evol. 3, 1890-1901. doi: 10.1002/ece3.548

van Beeck Calkoen, S. T. S., Kreikenbohm, R., Kuijper, D. P. J., and Heurich, M. (2021). Olfactory cues of large carnivores modify red deer behavior and browsing intensity. Behav. Ecol. 32, 982-992. doi: 10.1093/beheco/arab071

van Eeden, L. M., Eklund, A., Miller, J. R. B. B., López-Bao, J. V., Chapron, G., Cejtin, M. R., et al. (2018). Carnivore conservation needs evidence-based livestock protection. PLoS Biol. 16, e2005577. doi: 10.1371 /journal.pbio.2005577

Conflict of Interest: The authors declare that the research was conducted in the absence of any commercial or financial relationships that could be construed as a potential conflict of interest.

Publisher's Note: All claims expressed in this article are solely those of the authors and do not necessarily represent those of their affiliated organizations, or those of the publisher, the editors and the reviewers. Any product that may be evaluated in this article, or claim that may be made by its manufacturer, is not guaranteed or endorsed by the publisher.

Copyright (c) 2021 Kirkland, Hare, Daniels, Krofel, Rao, Chapman and Blossey. This is an open-access article distributed under the terms of the Creative Commons Attribution License (CC BY). The use, distribution or reproduction in other forums is permitted, provided the original author(s) and the copyright owner(s) are credited and that the original publication in this journal is cited, in accordance with accepted academic practice. No use, distribution or reproduction is permitted which does not comply with these terms. 